La juventud como protagonista en el último ciclo de protestas en Colombia Nuevas narrativas y disputas ante el aislamiento Marisabel García Acelas, Ildefonso Arias Perales Revista Argentina de Estudios de Juventud, dossier temático, e056, 2021 ISSN 1852-4907 | https://doi.org/10.24215/18524907e056 https://perio.unlp.edu.ar/ojs/index.php/revistadejuventud FPyCS | Universidad Nacional de La Plata La Plata | Buenos Aires | Argentina

\title{
LA JUVENTUD COMO PROTAGONISTA EN EL ÚLTIMO CICLO DE PROTESTAS EN COLOMBIA
}

\author{
NUEVAS NARRATIVAS Y DISPUTAS \\ ANTE EL AISLAMIENTO
}

\begin{abstract}
Youth as the Protagonist of the Last Cycle of Protests in Colombia. New Narratives and Disputes about Isolation
\end{abstract}

Marisabel García Acelas

marigarcia@uniminuto.edu | https://orcid.org/0000-0002-8614-4691

Ildefonso Arias Perales

ildefonso.arias@uniminuto.edu |https://orcid.org/0000-0002-2634-419X

Corporación Universitaria Minuto de Dios (UNIMINUTO)

Colombia

Palabras clave

juventud

movilización social narrativas pandemia

Keywords

youth

social mobilization

narratives pandemic

\section{Resumen}

El papel de la juventud colombiana en las recientes movilizaciones, ha traído consigo la emergencia de nuevos repertorios dentro de la contienda política. La reivindicación por la ampliación de la democracia y la exigencia de soluciones efectivas ante la crisis generada por las élites son resignificadas desde la acción colectiva bajo un fuerte componente simbólico que disputa el sentido desde lo común y pretende ampliar las demandas al resto de la sociedad.

\section{Abstract}

The role of Colombian youth in recent mobilizations has brought along the arrival of new repertoires within the political contest. The strive for the access to democracy, and the accountability of the elites in their role on the current crisis, is re-signified by challenging the meaning of it from a strong symbolic component; it is the purpose of this collective action to increase the reach of these demands to rest of the society. 


\title{
LA JUVENTUD COMO PROTAGONISTA EN EL ÚLTIMO CICLO DE PROTESTAS EN COLOMBIA
}

Nuevas narrativas y disputas ante el aislamiento

\author{
Por Marisabel García Acelas \\ e Ildefonso Arias Perales
}

Atrapados por la pauperización de sus condiciones de vida y las de sus familias, los/as jóvenes enfrentan las más duras consecuencias de la crisis del capitalismo y su fase neoliberal. El mercado los/as reconoce como libres y como diversos en tanto consumen y hacen parte del engranaje de acumulación capitalista, pero cuando la libertad y la diversidad son dispuestas para escenarios de emancipación social, la represión y el control de las élites se impone. No obstante, su espíritu y su talante transformador como combustible de grandes cambios sociales, los/as ha llevado a protagonizar el último ciclo de movilizaciones en el país. ${ }^{1}$

Jóvenes precarizados/as, en su mayoría urbanos/as, han desempeñado un papel fundamental en las manifestaciones. Las condiciones de pobreza que se expresan en los barrios marginados exponen a las mayorías trabajadoras a un acceso limitado de bienes y servicios, al desempleo, la informalidad, y el creciente aumento del costo de vida, lo que reduce las posibilidades de conseguir condiciones de vida dignas. A esta violencia económica, se suma el control presente en fenómenos como la «limpieza social», el micro tráfico, la estigmatización de los/as jóvenes de sectores populares, y las constantes amenazas a quienes fungen como líderes y lideresas sociales en sus comunidades.

En el contexto mundial, un nuevo ciclo de protestas se veía venir desde distintos puntos cardinales: Haití, Chile, Ecuador, Bolivia, Hong Kong y Francia. Los motivos para reclamar eran similares: desigualdad económica, desempleo, alzas en tarifas de servicios públicos, políticas de privatización y de despojo, desfinanciamiento de 
la educación, descontento ante las reformas pensionales y laborales, y una marcada indignación con, las cada vez más enraizadas, élites nacionales que definen políticas económicas a favor de sus intereses y de los conglomerados económicos transnacionales.

A comienzos de noviembre de 2019, en los barrios, universidades, parques y conversaciones cotidianas se iban colando varios temas de carácter nacional. Para los/as jóvenes, el desempleo generalizado, la casi nula posibilidad de acceso a la educación superior pública y la cada vez más lejana idea de algún día pensionarse, eran imágenes que se repetían incansablemente en los cuadros de la cotidianidad.

El panorama no podía ser más desalentador. Según el Departamento Nacional de Estadísticas, la tasa de desempleo de la población joven en el periodo noviembre 2018-enero 2019 fue de 18,1\% y en el trimestre móvil de noviembre 2019-enero 2020 fue de 20,2\% (DANE, 2020a). El gobierno nacional, encabezado por del presidente Iván Duque Márquez, anunció un paquete de reformas enfocadas en lo pensional, lo fiscal y lo laboral, y, como si fuera poco, era inevitable la sentencia del partido de gobierno por «hacer trizas» el Acuerdo de Paz firmado en La Habana, en 2016, entre el Estado colombiano y las Fuerzas Armadas Revolucionarias (FARC).

Razones para manifestarse, sobraban. Los/as más jóvenes vieron en las calles la posibilidad de expresar el descontento, y gestaron, así, un gigantesco oleaje que amenazó con hacer temblar las murallas de contención que salvaguardan a la élite política y corrupta de esta avasallada nación. El 21 de noviembre de 2019, se desató una inesperada y prolongada acción política que desbordó las expectativas de los sectores convocantes, los cuales ya habían evidenciado diversos actos desmovilizadores desplegados por el gobierno nacional con antelación a la fecha. Los sucesos de las siguientes semanas, marcados por toques de queda, amenazas de saqueo y asesinatos causados por la fuerza pública, no limitaron las convocatorias, cuya principal reivindicación ha sido la defensa de la protesta social como un derecho democrático.

\section{II}

Aunque en principio quienes estuvieron al frente de las movilizaciones fueron las centrales obreras, los/as maestros/as y los movimientos sociales tradicionales, poco a poco otros liderazgos emergieron y fueron tomando fuerza. Los/as jóvenes, 
en cantidades nunca antes vistas, cubrían las calles de las principales ciudades del país. Solo en Bogotá, la multitud que marchaba animada por las arengas y las batucadas hacía pensar que las adversidades podrían ser superadas. El sentimiento de indignación, la rabia contenida por años, la necesidad de ser escuchados/as y de hacerse sentir, era abrumadora. Las plazas se tiñeron de mil colores y la consigna era una sola, entre lo variopinto de la situación: «Nos quitaron tanto que nos quitaron hasta el miedo», rezaban varias de las pancartas que agitaban los/as manifestantes.

Sin duda, uno de los sectores que asumió un compromiso memorable en las movilizaciones fue el movimiento estudiantil, que cuenta con una extensa trayectoria de luchas dignas por la defensa de la educación. Son organizados, tienen los bríos de la juventud y conocen la historia del país-región, no solo desde Bogotá sino desde sus territorios. Cuentan con una capacidad de convocatoria envidiable, no tiene problemas con acampar, trasnochar, tomar agua panela y pan, caminar, saltar, cantar, controvertir, reunirse, preparar, estudiar, acordar, planear, avanzar, apaciguar y retomar, elementos necesarios a la hora de protestar y que, en algunos sectores, son más restringidos por su misma naturaleza o por los cambios de época. Como todo proceso, tiene sus tensiones internas y sus propias contradicciones, lo que es aprovechado por los sectores conservadores más recalcitrantes del país, que sueñan con estudiantes dóciles, alineados en sus pupitres, desprovistos de capacidad crítica y de espaldas a la realidad social.

Uno de los reclamos de los/as manifestantes estaba relacionado con la posibilidad de abrir el diálogo frente a las medidas económicas del gobierno, por considerarlas reduccionistas y nefastas para el pueblo colombiano. Entre ellas, la desfinanciación de la educación pública y el incumplimiento de los acuerdos a los que llegaron los/as estudiantes y los/as profesores/as manifestantes de 32 universidades públicas, en 2018, en la Mesa de Diálogo con el gobierno, y que incluían reformas de fondo al Instituto Colombiano de Crédito Educativo y Estudios Técnicos en el Exterior (ICETEX), el saneamiento de los pasivos de las instituciones de educación superior, y la ampliación de fuentes y de recursos para la educación pública (Jíménez, Libreros \& Mora, 21/02/2019).

Las jornadas de movilización evidenciaron un renovado repertorio frente a la convocatoria. La creatividad artística jugó a favor de quienes habitaron por varios días los espacios públicos por fuera de las lógicas del mercado y con la intención 
de atiborrar las calles de gente para hacer sentir que no estaban apabullados y que en tiempos de crisis mirarse cara a cara es imprescindible. Por eso, el $21 \mathrm{~N},{ }^{2}$ la gente en resistencia popular nutrió las arterias de las ciudades $y$, por donde habitualmente transitan miles de automóviles, los/as caminantes arengaban al unísono: «A parar para avanzar! ¡Viva el paro nacional! Porque, antes que nada, ¡La Revolución es una fiesta!» (Díaz, 2020).

Las noches con sus días sufrieron cambios. En las mañanas, la muchachada, en vez de ir a sus aulas de clase, se proveía de agua, algo de comida para compartir con los/as compañeros/as y, pancarta en mano, enfrentaba las calles. Lo común cobraba fuerza y el trabajo solidario iba desde la logística en los recorridos hasta acompañarse a sus casas una vez que terminaban las movilizaciones. Había que cuidarse, pues la represión policial estaba a la orden del día en cualquier esquina.

En las noches, los colectivos trataban de organizarse en asambleas populares. En los parques, al calor de una fogata se planeaban las acciones para los siguientes días, se discutían las posturas. En consenso, se decidían las rutas, se escribían las arengas, se perfilaba el objetivo del próximo recorrido. También, se comunicaban los avances y los retrocesos de la mesa de diálogo integrada por el comité del paro. El trabajo era animado por los/as mismos/as jóvenes al ritmo de músicas, obras de teatro callejero, saltimbanquis, entre otras expresiones artísticas y culturales presentes en estas movilizaciones.

Ante la pandemia, el gobierno implementó políticas aperturistas que benefician a los gremios económicos, acompañadas de medidas propias de un estado de excepción que limitan los derechos civiles y políticos. Cada vez, es más evidente la concentración de los poderes en el Ejecutivo y los datos económicos no dan tregua: «La tasa de desempleo juvenil para el trimestre móvil mayo-julio 2020 fue de 29,7\%, lo que significó un aumento de 12,2 p.p. frente al mismo trimestre del año 2019» (DANE, 2020b).

Frases como «estudien vagos», pronunciada en el Congreso por una senadora de la república durante un homenaje a las víctimas del conflicto armado, y «de qué me hablas viejo», enunciada por el Presidente cuando le preguntaron por un bombardeo a manos del Ejército en el que murieron niños/as, son un reflejo de la negación sistemática de los conflictos sociales por parte de la clase política dirigente en 
Colombia. Un país con problemas estructurales demanda de transformaciones profundas, que vinculen a los sectores sociales históricamente excluidos.

El ímpetu de la juventud le permite romper el miedo resultante del encierro y manifestarse ante el abuso de poder. Muestra de ello es que luego del pico de contagios, se presentó la última acción colectiva espontánea que cuestionó la represión que venía en ascenso fruto del encierro. La sigla ACAB (All Caps Are Bastard) protagónica como emblema, sintetizó parte del sentimiento de indignación por los asesinatos de Dylan Cruz (noviembre de 2019) y de Javier Ordóñez (septiembre 2020), así como por la oleada de masacres a jóvenes de áreas periféricas, que se suma a la de líderes y lideresas sociales.

Cuando la represión policial fue brutal e intentó apaciguar los ánimos, aparecieron otras formas de narrar. El ensordecedor ruido de las cacerolas en los parques, en las calles, desde las ventanas, inquietó a quienes cómodamente hacían oídos sordos. Esta resignificación involucró a niños/as, abuelos/as y trabajadores/as a quienes sus empresas obligaban a asistir, como fuera, a la jornada laboral, y que encontraron en el cacerolazo nocturno una posibilidad de manifestar ante sus gobernantes el amplio apoyo a las movilizaciones sostenidas por sus hijos/as, nietos/as, sobrinos/as y amigos/as.

Con las movilizaciones, la pedagogía saltó las paredes de la escuela y se llenó de pueblo. En las jornadas, profesores/as y estudiantes compartieron conocimiento y escucharon los justos reclamos de quienes no entendían por qué su cotidianidad se veía alterada de forma tan inusual. La juventud hizo un alto en el camino para explicar a los/as adultos/as, a los/as trabajadores/as informales y a todo el que se encontrara en la calle, el paquetazo de reformas laborales y tributarias anunciadas por el gobierno y cómo estas afectarían, incluso con mayor fuerza, su vida cotidiana.

\section{III}

Existe una reinvención de los marcos interpretativos ${ }^{3}$ impulsada por la juventud y caracterizada por la puesta en marcha de otras narrativas que pretenden manifestar inconformidad: construir sentidos dirigidos a impactar a su generación y a romper el ostracismo al que invita la pandemia. 
En el último ciclo de movilizaciones, ha sido sumamente llamativa la incorporación de símbolos y de imágenes de películas que representan lucha y justicia social. Las calles del país, principalmente en las urbes, se llenaron de máscaras de «V de vendetta» y del «El Guasón» o de disfraces de «La Casa de Papel», visibilizando una clara postura antisistema recreada por la juventud movilizada. Estas apuestas comunicativas y performativas, sin duda están atravesadas por las creencias, los estilos y las preferencias de sus creadores/as. En esa perspectiva, no están exentas de la influencia de la cultura dominante, pero quienes las apropian toman aquello que puede ser reconfigurado para realizar nuevas propuestas que permitan condensar sus reivindicaciones, evidenciando un puente entre la cultura de masas y la cultura local de los/as jóvenes.

Otro elemento interesante para la reflexión es la masificación de carteles que los/as manifestantes llevan en forma individual, poco habituales en las movilizaciones hasta hace pocos años. Dentro del repertorio de las acciones colectivas, las pancartas de los gremios, de los movimientos políticos y sociales, así como de los sectores más reconocidos, marcaron durante décadas el carácter reivindicativo en las calles. Sin embargo, progresivamente, han aparecido carteles escritos o pintados a mano que ponen de manifiesto demandas que, aunque parten del sentir individual, lo trascienden y apuntan a la consolidación de lo colectivo forjado desde las narrativas artísticas y políticas personales.

La creatividad ha sido protagonista. Los letreros tienen la capacidad de innovar, de proponer y de arriesgar con nuevas puestas en escena que revitalizan y que empatizan con quienes se identifican en la reivindicación. Al usar carteles personalizados, cada quien expresa su inconformidad con las políticas implementadas por el gobierno o con el histórico incumplimiento hacia diversos sectores sociales. Carteles, máscaras y disfraces se convierten en una opción de expresión popular, alternativa y diferente que les da voz a quienes se movilizan. De hecho, hacen parte de prácticas propias de la comunicación popular que cuentan con el potencial de generar otras opciones de vida, canalizando la energía y los intereses de la juventud en los barrios, para hacer frente a los procesos de violencia y a los conflictos locales. Desde abajo, estos repertorios cuestionan las enormes brechas económicas, generacionales, políticas y de género presentes en la sociedad, y cuyos/as impulsores/as padecen cotidianamente. 
Lo que los medios tradicionales callaron, otras alternativas comunicativas lo expresaron de forma contundente. El panfleto, el folleto, que otrora eran impresos, circularon por Facebook, Instagram y Whatsapp en forma de memes y podcast. Con diseños artísticos muy bien logrados y piezas musicales concretas, los/as jóvenes llamaron la atención de la sociedad y demandaron el derecho a la protesta social. La comunicación desde lo local se armó de argumentos, de consignas, de un teléfono móvil y, en un par de minutos, las noticias estallaban en las redes. Un punto de encuentro, la hora, una frase alusiva, una imagen recursiva y la acción colectiva se tornó contundente, prolongada y nutrida.

Sin duda, las luchas feministas también han enmarcado el discurso y la recreación simbólica de estas movilizaciones. Los pañuelos verdes y morados, que demandan la despenalización del aborto y visibilizan la resistencia de las mujeres, son cada vez más frecuentes. El cántico «Un violador en tu camino», del colectivo Lastesis, ha sido apropiado durante las marchas como rima para visibilizar la desigualdad y la violencia de género, incluyendo realidades locales que se suman a un grito de época por la libertad. Precisamente, son las jóvenes quienes han convertido los distintivos de luchas globales en una poderosa herramienta de concientización, permitiendo que la acción colectiva se irradie a partir de los lazos compartidos, las experiencias comunes, y los significados y los sentidos en los que se coincide.

Entre tanto, los tapabocas característicos de la actual pandemia también se han convertido en un lienzo para comunicar. Rostros de Mafalda, de Frida Kahlo y el nombrado mural «¿Quién dio la orden?», referido a las ejecuciones extrajudiciales cometidas por militares en el país, dan forma a los semblantes de las últimas movilizaciones. Así, pues, un accesorio que surge para contener la difícil situación de salud pública y para proteger la vida, es convertido en un poderoso anuncio con la capacidad de visibilizar apuestas políticas, de atraer, de congregar y de nutrir los repertorios de las acciones colectivas.

Las paredes de las principales ciudades no son la excepción. Durante las últimas décadas, han funcionado como amplificadores de un contundente nivel de crítica y de cuestionamiento al status quo. En el marco de la pandemia, los mensajes, las pintas y los grafiti se han renovado, invitando a superar la angustia y a retomar las movilizaciones que dieron cierre al año 2019, y poniendo en el debate público hechos y discusiones normalizados por el radar informativo de los grandes medios. 
En la actualidad, las movilizaciones en Colombia tienen otros colores, otros protagonistas, suenan diferente, se escucha con atención a la filarmónica pero también se respetan las líricas que nacen del barrio. Se enseña, se aprende, se construye en y para lo colectivo. Se resiste con fuerza, con inteligencia y «la primera línea», en donde ahora batalla el personal médico para controlar el virus, también fue conformada por estudiantes armados de valor y creatividad para batallar contra la represión y el mal gobierno. En las calles, después de nueve meses de pandemia, el país huele a fiesta, la gente se prepara para un parto, un nuevo $21 \mathrm{~N}$ se avecina, ahora, con máscaras para defenderse del covid-19, y con más creatividad y capacidad organizativa para defender el derecho a defenderse.

\section{Referencias}

Departamento Administrativo Nacional de Estadísticas (DANE).

(11 de marzo de 2020a). Mercado laboral de la juventud. Boletín técnico.

Gran encuesta de hogares. Recuperado de

https://www.dane.gov.co/files/investigaciones/boletines/ech/juventud /Bol_eje_juventud_nov19_ene20.pdf

Departamento Administrativo Nacional de Estadísticas (DANE). (septiembre de 2020b). Panorama sociodemográfico de la juventud en Colombia. Recuperado de https://www.dane.gov.co/files/investigaciones/genero/informes/infor me-panorama-sociodemografico-juventud-en-colombia.pdf

Díaz, L. (20 de abril de 2020). Sinfonía de un paro en Suacha.

[Documental]. YouTube. Recuperado de https://www.youtube.com/watch?v=F9wxvx_2f5s\&t=906s

Jiménez, C., Libreros, D y Mora, A. (21 de febrero de 2019). PND arriesga cumplimiento del Acuerdo por la educación superior pública. UNperiódico. Recuperado de https://unperiodico.unal.edu.co/pages/detail/pnd-arriesgacumplimiento-del-acuerdo-por-la-educacion-superior-publica/ 
Mc Adam, D. (1999). Movimientos sociales, perspectivas comparadas.

Oportunidades políticas, estructuras de movilización y marcos

interpretativos culturales. Madrid, España: Istmo.

\section{Notas}

1 Las reflexiones que se presentan en este escrito son una construcción colectiva producto del ejercicio etnográfico y de la acción participante realizados por el autor y por la autora durante las movilizaciones de 2019 y 2020 vividas en el país vividas en el país.

2 Esta es una de las referencias que aparece en el marco de las movilizaciones, denominar al 21 de noviembre con la abreviatura " $21 \mathrm{~N}$ ", una combinación alfanumérica que dio resultado al momento de convocar. Luego se extendió para nombrar el $22 \mathrm{~N}, 23 \mathrm{~N}, 24 \mathrm{~N}$, $25 \mathrm{~N}$ y el 1D, 2D, 6D, 8D para el mes de diciembre y ha permanecido para convocar a las movilizaciones del mes de septiembre de 2020 (21S), cuando se levantó el confinamiento a causa de la pandemia por covid-19.

3 A estos significados comunes a través de los cuales los sujetos comienzan a definir su situación, Mc Adam (1999) los denomina marcos interpretativos o procesos enmarcadores, y los define como esfuerzos estratégicos conscientes, realizados por grupos de personas en orden de forjar formas compartidas de considerar el mundo y así mismo que legitimen y muevan la acción colectiva. 